\title{
Engenharia, manutenção e operação em processos contínuos: elementos para o projeto de fronteiras organizacionais móveis e interpenetrantes
}

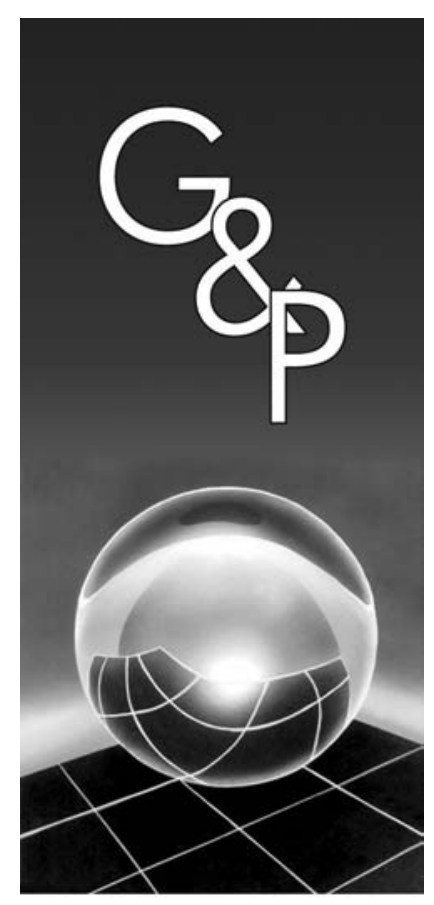

Integração engenharia - operação - manutenção. Sociotécnica.

\section{Resumo}

\author{
Mario Sergio Salerno \\ Marcelo Crescenti Aulicino
}

Nos processos contínuos há uma forte participação dos profissionais da manutenção e da engenharia na operação do sistema de produção. Manutenção e engenharia atuam diretamente na operação quando especificam parâmetros de controle do processo, intervêm em eventos previstos ou não, resolvem problemas de grande complexidade tecnológica e logística, e modificam processos e equipamentos para obter melhores resultados. Por outro lado, é a operação que detém o conhecimento de como realizar manobras, da inércia das instalações para responder a comandos, dos efeitos práticos do encadeamento e desdobramento de manobras, da alteração de parâmetros de controle, ou da indisponibilidade de equipamento, influenciando decisivamente o espectro de ação da engenharia e da manutenção. Não obstante, mesmo as mais avançadas e contemporâneas abordagens para projeto organizacional não apresentam critérios integrados de projeto para essas três decisivas funções, que se interpenetram. Ou seja, abordar-se-á não a interface tradicional, estática, entre as áreas, mas a sua interpenetração e ação de operação. Nesses termos, o objetivo deste trabalho é contribuir na construção de um quadro de referência e de critérios de projeto integrado das três áreas, a partir de estudo de caso de refinaria de petróleo multiprocessos, caso típico de processo contínuo.

Palavras-chave: Projeto organizacional. Organização do trabalho. Processos contínuos. - Integração engenharia - operação - manutenção. Sociotécnica.

\section{Introdução}

O presente trabalho nasce de uma questão simultaneamente metodológica e prática, não resolvida pelo estado da arte dos estudos, métodos, procedimentos ou regras de projeto organizacional. Há uma vasta literatura sobre organização de uma forma geral, mas aquela que foca conceitos e métodos de projeto organizacional é muito mais escassa. Ainda, há características dos processos contínuos que implicam num olhar específico. Neles, o trabalho de operação é caracterizado pelo acompanhamento e controle dos processos de fabricação, com as conseqüentes intervenções para prevenir problemas, para ajustes no estado do processo, correção de problemas já evidenciados para além do grupo de operadores diretos. Entretanto, essas intervenções não se limitam às ações dos operadores da produção e nem sempre são deflagradas por estes. Nos procedimentos de operação há uma forte participação dos profissionais da manutenção e da engenharia da fábrica, que determinam à produção parâmetros de controle do processo, resolvem problemas de grande complexidade tecnológica e logística e modificam os processos e equipamentos para obter melhores resultados (FERREIRA; IGUTI, 1996; MARX, 1997; RAMOS FILHO, 1997; AULICINO, 1998; KHURANA, 1999; BOUYER; SZNELVAR, 2005).

A necessidade de interação entre profissionais da produção e profissionais de outras áreas depende da complexidade dos sistemas. Podem-se considerar dois campos como relevantes para definir a complexidade dos sistemas de produção: a complexidade logística, que resulta de grandes volumes de transações e tarefas ou, ainda, da diferenciação de produtos, e a complexidade tecnológica, relacionada à complexidade inerente do sistema e das suas tecnologias para produtos e processos.

Os processos contínuos de produção são apontados como os mais complexos, em razão das tecnologias empregadas e das relações de fluxo entre os diversos processos 
operacionais e plantas que compõem cada fábrica (AULICINO, 1998; KHURANA, 1999). A esse respeito, Khurana (1999) considera que em razão da complexidade tecnológica dos processos, engenheiros e técnicos precisam saber não apenas o como, mas também o porquê, para entender as interações entre as etapas dos processos e serem capazes de solucionar os problemas que se apresentam.

Invertendo a seqüência usual, começaremos discutindo a metodologia da pesquisa e apresentando o caso. Julgamos que a construção do problema - da questão de pesquisa - fica facilitada se tratada a partir do caso. $\mathrm{O}$ foco será a descrição e análise das interfaces entre os três domínios em questão, o que requer uma discussão do caso mais extensa do que a habitual. Caracterizado o problema e o caso, procederemos à discussão da literatura pertinente, tendo como eixo os desenvolvimentos ao redor da sociotecnologia moderna e desdobramentos (SITTER; HERTOG; DANKBAAR, 1997; SALERNO, 1999 e 2007). À luz da análise teórica, o caso será utilizado para a proposição de elementos para um método, um roteiro de projeto organizacional considerando a integração das dimensões de operação, manutenção e engenharia.

\section{As interfaces na produção por processos contínuos: o caso da refinaria de Cubatão}

Para embasar a discussão é estudado o caso da Refinaria Presidente Bernardes de Cubatão - RPBC, da Petrobras. Os dados apresentados foram obtidos por dois métodos: observação participante e entrevistas realizadas com operadores de produção, técnicos da manutenção, pessoal da engenharia e gerentes.

\subsection{Metodologia de pesquisa de campo}

A observação participante que, grosso modo, inspirou-se em Thiollent (1997), foi feita por um dos autores que trabalha nessa refinaria, onde já desempenhou diferentes funções na operação, manutenção e engenharia, que incluem a coordenação de turnos de produção, o planejamento e coordenação de paradas de manutenção e o planejamento e controle de projetos de grande porte. Dessa forma, houve facilidade de acesso a documentos e conhecimento prévio e profundo do sistema estudado. A observação não foi aleatória, mas estruturada para focar os problemas de interfaces organizacionais, que também foram o foco das entrevistas. Assim, privilegiou-se o acompanhamento e análise de eventos envolvendo, potencial ou efetivamente, participação da operação, da manutenção e da engenharia. Com isto, foram estudados os problemas de divisão do trabalho, as formas de coordenação levadas a cabo e seus limites, os atritos e as lacunas de competência, e o limite da atuação de cada uma das funções.
As entrevistas seguiram roteiro elaborado a partir da abordagem da sociotecnologia moderna, que será discutida mais à frente. Foram feitas dez entrevistas abertas, baseadas em roteiro estruturado, sem os limites rígidos dos questionários fechados, para permitir que os entrevistados pudessem abordar aspectos que considerassem relevantes não relacionados anteriormente pelos pesquisadores. Abrangeram profissionais de todas as áreas (ou dimensões, funções) objeto da pesquisa, e vários cargos (operadores, técnicos de operação, engenheiros, técnicos de manutenção e gerentes), de modo a colher dados segundo diferentes visões e minimizar possíveis vieses, não só oriundos da relação entrevistador - entrevistados, como também da observação participante (EISENHARDT, 1989; VOSS et al., 2005). Para controle metodológico, foram feitos levantamentos semelhantes, ainda que em menor extensão, em outra empresa de processo contínuo. Isso visou controlar distorções introduzidas pela natureza de uma observação participante, como a possível falta de distanciamento crítico e viés de seleção com relação à interpretação das entrevistas e dos eventos analisados, além de testar as possibilidades de generalização para outras empresas com o mesmo tipo de processo de trabalho.

\subsection{O estudo de caso: análise dos proces- sos, das funções, das interfaces e seus problemas}

A RPBC é a refinaria de petróleo mais complexa do Brasil, ou seja, a que possui a maior diversidade de unidades de processamento para refino de petróleo, gerando também uma grande diversidade de fluxos de produtos intermediários que vão compor uma grande gama de produtos finais. É uma das primeiras refinarias do país, tendo passado por diversas reformas para substituição de equipamentos, ampliação e modernização. Na década de 90, foram instalados sistemas digitais de controle distribuído (SDCD) em todas as unidades de processos, bem como sistemas de controle avançado, que passaram a controlar as principais variáveis dos processos de fabricação por meio de algoritmos interligados ao SDCD. Novas malhas de controle avançado continuam a ser instaladas, ao mesmo tempo em que as existentes são aperfeiçoadas.

A estrutura organizacional da RPBC pode ser vista na Figura 1. As dimensões consideradas são: engenharia (engenharia 1 + engenharia 2); operação (produção + transferência e estocagem); e manutenção (manutenção + inspeção de equipamentos). As gerências setoriais e supervisões existem onde há uma quantidade significativa de pessoas que realizam atividades de execução, como operadores e profissionais de manutenção. Os coordenadores trabalham com equipes menores e atuam em atividades que demandam coordenação lateral. A seguir serão destacadas as áreas que têm atuação direta na atividade de produção. 


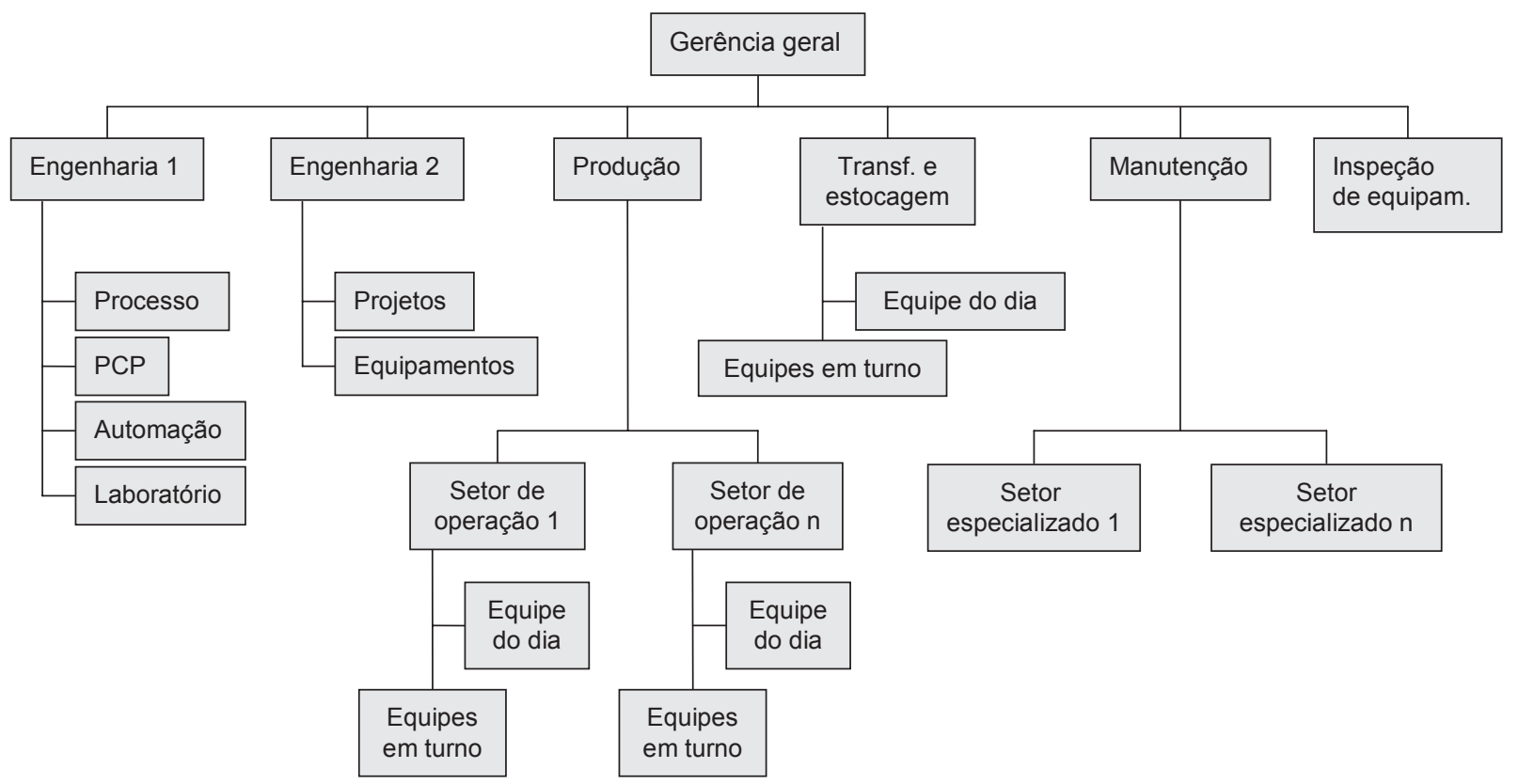

Figura 1. Organização estrutural do sistema de produção da RPBC. (SALERNO; AULICINO, 2008).

A área de produção é encarregada da operação das unidades de processo, que realizam a transformação do petróleo em produtos intermediários ou finais. É dividida em gerências setoriais por grupos de unidades de processo. A divisão das equipes, dentro de cada gerência setorial, segue os critérios tradicionais da sociotécnica (CHERNS, 1979): tecnologia (fluxos e encadeamento das operações), tempo (turnos) e território (localização física dos processos e do aparato de controle). Em cada turno há um supervisor por gerência setorial e um coordenador de turno, que respondem pela coordenação geral do sistema de produção. Através dos técnicos de operação e operadores em horário administrativo se realizam a maior parte das interfaces com a engenharia e a manutenção.

Atualmente, uma gerência específica opera o sistema de tubulações e tanques através do qual o petróleo é recebido, armazenado, preparado e enviado às unidades para refino. Recebe e estoca correntes intermediárias dos processos e correntes para produtos finais, compondo os produtos finais com as correntes recebidas. À semelhança da gerência de produção, os operadores formam equipes com um supervisor por turno e há uma equipe de suporte ao gerente no horário administrativo.

A Função engenharia conta com duas gerências. Uma é equivalente à engenharia de processos, realizando acompanhamento e otimização dos processos de fabricação. Estuda os parâmetros dos processos físico-químicos de transformação e os avalia tendo em vista a qualidade dos produtos, a economia energética, a minimização de perdas, o melhor rendimento da matéria-prima, etc. Com esse foco, especifica valores para os parâmetros de controle dos processos de fabricação, dá assessoria técnica às gerências de operação, elabora projetos conceituais de alterações dos processos, realiza projetos de automação, faz a programação e controle da produção, e acompanha e estuda a qualidade dos produtos. As atividades de análises de laboratório e a programação da produção estão a ela ligadas. É formada por uma equipe de engenheiros de processo ligada ao gerente, uma equipe de programação de produção, uma equipe de engenharia de automação de processos, cada uma com um coordenador, e uma gerência setorial que responde pelas análises de laboratório.

A outra gerência da função engenharia é responsável pelo projeto básico, detalhado e implementação de melhorias operacionais, ou seja, modificações técnicas nas unidades de produção para eliminar problemas de confiabilidade, aumentar a eficiência dos equipamentos e sistemas, modernização, etc. Estuda falhas de equipamentos e aponta soluções. Para cada uma dessas atividades, há uma equipe composta por engenheiros e técnicos, cada uma delas com um coordenador.

A manutenção responde pela conservação e reparo dos equipamentos. É composta pela gerência, gerências setoriais divididas por especialidades, e supervisores. Vários serviços são terceirizados.

Para realizar o planejamento, programação e coordenação dos trabalhos de manutenção foram criadas equipes de continuidade operacional, segmentadas conforme as gerências setoriais da operação, e compostas por supervisores de cada especialidade de manutenção, operadores e técnicos de segurança. Têm a função de planejar, programar, coordenar e supervisionar, no caso de mãode-obra própria, ou fiscalizar, no caso de mão-de-obra de terceiros, as intervenções de manutenção. Cada gerência 
setorial da manutenção possui ainda equipes técnicas e de execução responsáveis pelos serviços de oficina, elaboração de contratos, monitoramento das condições de confiabilidade dos equipamentos, gestão de sobressalentes, trabalhos técnicos, etc.

Devido à importância do monitoramento da integridade física dos equipamentos, há uma gerência específica para tratar desse assunto, que avalia o desgaste e a deterioração dos equipamentos, recomenda medidas para reparo ou substituição, propõe melhorias como substituição de materiais ou encaminha problemas e sugestões para estudo da engenharia.

Tipicamente, otrabalho diário realizado pelos operadores começa com o conhecimento do estado dos processos, por meio de relatos verbais dos operadores do turno anterior, de leitura dos últimos relatórios dos turnos de operação e de instruções operacionais emitidas pelas gerências, de verificação de telas do sistema de controle dos processos e de verificação in loco das condições dos equipamentos. A troca dessas informações entre os operadores de uma equipe e com outras equipes possibilita reconstruir os modelos mentais do processo que serão as referências para as atividades de monitoração e controle, e para definir as ações que serão tomadas no decorrer do turno de trabalho (AULICINO, 1998; DANIELLOU, 1986).

\section{Como as interfaces emergem e se interpenetram e por que tratá-las no projeto organizacional}

As interfaces nascem devido à divisão do trabalho em "unidades" - subsistemas, funções, elementos transversais do sistema (como qualidade, RH, etc). Diversas formas de coordenação podem ser utilizadas para tratamento das interfaces. Vários autores consideram que, em sistemas integrados e complexos, a eficiência depende mais da qualidade das interfaces do que da racionalização das atividades em cada função em si (VELTZ, 2000; WORLEY; LAWLER III, 2006; GRATTON et al., 2007).

$\mathrm{Na}$ sua rotina operacional, os operadores procuram manter o processo o mais estável possível, pois alterações nas suas variáveis podem acarretar variações na qualidade de produtos, interrupção da produção, emissão de poluentes, etc. Ocorrências como alterações na qualidade da carga (matéria-prima) das unidades operacionais, equipamentos funcionando fora das condições especificadas, mudanças de programação da produção e panes de equipamentos, entre outros, introduzem variações nos processos de fabricação que podem provocar a perda de estabilidade desejada e exigem atuação das equipes de operadores para mantê-los sob controle. Nas ocorrências em que há dificuldade de se diagnosticar as causas, quando as soluções não são triviais ou apresentam dificuldades para sua implementação, além da equipe de apoio do próprio setor, pode ser constatada participação significativa da manutenção e da engenharia no restabelecimento das condições operacionais, na análise das causas e no aprendizado, mediante a emissão de recomendações de incorporação aos processos de medidas corretivas e preventivas. Ou seja, as fronteiras organizacionais se interpenetram, pois não se trata aqui de uma interface tradicional, pré-definida.

Por exemplo, a ocorrência de pane no compressor de gases da unidade de craqueamento catalítico exige atuação rápida e conjunta das três funções para identificar o problema e suas causas (Falha mecânica? Falha no controle eletrônico do equipamento? Condições inadequadas dos processos? Falha no sistema de utilidades? Outra causa?), proceder aos reparos e fazer a unidade de processo retornar à operação de modo seguro. Mais ainda, quais providências tomar para que a ocorrência não se repita? A resposta a essas perguntas e às ações a serem tomadas não se limitam ao domínio estrito da operação.

Por outro lado, os engenheiros de processo, a quem cabe estudar otimização dos processos, procuram novos parâmetros de controle de forma a reduzir o consumo de energia, alterar as taxas de produção de determinado produto, alterar as composições de produtos, melhorar o atendimento às especificações de qualidade, reduzir emissões para a atmosfera, etc. Em consequiência, especificam novos valores dos parâmetros de controle que podem alterar as condições de funcionamento dos equipamentos e as condições de estabilidade dos processos, alvo da ação dos operadores. Localiza-se aí um possível conflito de objetivos e de atuação. Mesmo que todos concordem com os objetivos perseguidos, será que os operadores, no seu conhecimento da operação daquele processo e daquela instalação, concordam com a especificação da Engenharia quando os engenheiros propõem modificações nos parâmetros dos processos de produção? Como essas especificações interferem nas estratégias operatórias e na representação do estado dos processos pelos operadores? (DANIELLOU, 1986; SALERNO, 1999; BOUYER; SZNELVAR, 2005). Será que os engenheiros avaliaram adequadamente os impactos dessas especificações no desgaste e na integridade dos equipamentos e na estabilidade operacional do processo de produção? Ou de outra forma, como os operadores podem contribuir para o sucesso da condição que aqueles engenheiros estão buscando?

Os operadores dos turnos, que executam o trabalho diário de monitoramento dos processos e que são os primeiros a atuar quando ocorrem variações, precisam participar do entendimento das novas situações que se apresentam. Há necessidade de intercompreensão mútua dos profissionais que atuam em cada uma das funções, $o$ que envolve aspectos cognitivos e normativos da comunicação (SALERNO, 1999; ZARIFIAN, 1996). Ou seja, intercompreensão mútua entre os diversos saberes 
e competências (aspecto cognitivo) e intercompreensão mútua sobre o que está em jogo no momento, sobre quais critérios de decisão seguir (aspecto normativo).

Além disso, alterações introduzidas nos processos podem levar os equipamentos a trabalhar fora das condições de projeto, alterar taxas de desgaste dos equipamentos e introduzir novos modos de falhas, demandando estudos e ações da manutenção e da engenharia visando à confiabilidade e continuidade operacional, inclusive promovendo alterações nos equipamentos e nos procedimentos para operá-los. Isso traz à cena a participação das equipes de manutenção e do pessoal de engenharia de equipamentos.

Com a informatização, o acesso à informação pode se dar via telemática, e não apenas no centro de controle. Passa a haver um compartilhamento da operação das unidades entre os operadores e os engenheiros e técnicos de automação de processo, que projetam, implementam e mantêm os controles avançados; com os engenheiros de processo, que acompanham as operações à distância e identificam situações que podem acarretar problemas futuros; e com o pessoal de manutenção, que pode monitorar à distância parâmetros de operação das máquinas e alertar a operação sobre a regulagem desses parâmetros, a fim de evitar ocorrências causadoras de falhas. A questão relevante e pertinente é como as relações entre essas funções são organizadas de modo a se obter a maior eficiência na operação das plantas.

Foram observadas duas posturas distintas por parte dos operadores com relação aos controles avançados: aqueles que consideram o controle avançado uma "caixa preta" com a qual se deve conviver, e aqueles que procuram entender o seu funcionamento e interpretar as respostas que ele dá. Algumas explicações apresentadas para a primeira atitude são necessidade de conhecimentos (referencial técnicocientífico) para entender seu funcionamento e distância, tanto organizacional como física, entre os operadores e o pessoal de automação. Foi relatado por operadores e engenheiros entrevistados que os operadores que adotam a segunda postura têm maior interação com o pessoal da engenharia e da manutenção, contribuindo para aumentar a capacidade de controle do processo por todas as áreas. Ou seja, têm maior possibilidade de se engajarem num esquema de coordenação via comunicação cognitiva.

Aliás, a distância física foi apontada pelos entrevistados como um fator de dificuldade não apenas entre os diferentes domínios, mas também dentro de cada um deles. A distância entre os escritórios do pessoal de gerência e equipes de suporte das salas de controle e das unidades de produção na RPBC pode chegar a dois quilômetros. Por outro lado, existe a proximidade física desses escritórios com as equipes da engenharia.

Outra situação de interface/interpenetração relevante são as intervenções de manutenção. Mesmo quando programadas, elas podem ocasionar alterações nas condições de controle do processo, seja pela falta do equipamento em manutenção, seja pela necessidade de manobras operacionais para sua liberação para a intervenção desejada ou por provocarem situações diferentes na operação dos processos durante o período de intervenção. Por exemplo, a retirada de operação de um instrumento de controle pode exigir dos operadores, ações não rotineiras para monitoramento daquela parte do processo ou mesmo de outras partes inter-relacionadas.

Os exemplos acima mostram eventos em que Operação, Engenharia e Manutenção interferem na produção. Tudo se passa como se, nessas ocasiões, engenheiros e manutentores passassem a fazer parte da Operação. Em todas elas, o desempenho do sistema de produção depende não só da atuação de cada um dos domínios, mas de como acontecem interações entre eles e da integração das suas ações. A pesquisa realizada evidenciou que a coordenação dos trabalhos nos sistemas tecnologicamente complexos abrange também outras dimensões: uma dimensão cognitiva, relativa à integração dos conhecimentos e habilidades para acompanhar e interpretar as tendências e variações das variáveis dos processos de produção e para decidir como tratar situações não rotineiras; uma dimensão normativa, relativa à redefinição das regras e procedimentos de operação do aparado técnico, de intervenções de manutenção e, mesmo, de elaboração e execução de projetos de engenharia.

\section{Conceitos e métodos para projeto da organização do trabalho e das interfaces entre produção, manutenção e engenharia}

Para tratar o projeto organizacional do trabalho considerando a atuação conjunta da operação, manutenção e engenharia no sistema de produção, lançaremos mão da chamada sociotecnologia moderna. Essa abordagem apresenta desenvolvimentos da teoria organizacional que se seguiram à aplicação dos princípios da sociotécnica clássica, e que representaram um movimento em direção a uma teoria e prática de projeto organizacional na década de 90 . Ela visa o projeto de estruturas organizacionais simples, ou seja, com poucas divisões (unidades) e trabalho complexo, ao invés da tradicional estrutura complexa, com muitas unidades e trabalho simples. Os conceitos básicos para projeto organizacional podem ser apresentados em quatro itens (SITTER et al., 1997; SALERNO, 1999, 2007):

a) o projeto da estrutura organizacional deve se basear nas interações entre os subsistemas funcionais (vendas, projeto do produto, planejamento, fabricação, etc.) e os aspectos que lhes são transversais, como qualidade, logística, manutenção e pessoal. Este é o conceito de 
projeto integral, envolvendo as funções (subsistemas do sistema de produção) e os atributos gerais do sistema de produção (ou aspectos do sistema);

b) o projeto deve incrementar a capacidade de controle do sistema, ou seja, prever e facilitar a ação sobre aleatórios e eventos (como pane numa instalação ou, menos radicalmente, a mudança de estratégia para maximizar ou minimizar a extração de determinadas frações, como diesel e gás liquefeito de petróleo, em função de necessidades de abastecimento do mercado) e não apenas a ação sobre atividades pré-mapeadas e prescritas (como no caso de abertura de válvula). $\mathrm{O}$ conceito de dirigibilidade trata, portanto, da capacidade do sistema ser pilotado, dirigido, operado em função de objetivos mutantes e não conhecidos a priori;

c) definição conjunta da estrutura de produção e da estrutura de controle para identificação e análise dos parâmetros estruturais (da estrutura organizacional) ligados às probabilidades de variações no sistema. A necessidade de controle deriva do desenho da estrutura organizacional, não é uma variável independente. Esse conceito, também conhecido como conceito duplo de estruturas de produção e de controle, está relacionado à capacidade de reduzir as variações (perturbações) no sistema, ou seja, de melhorar a sua dirigibilidade; e

d) definição dos parâmetros estruturais que conformam a estrutura organizacional geral do sistema de produção, compreendendo seus subsistemas funcionais e os aspectos transversais. $\mathrm{Na}$ realidade, os conceitos anteriores se traduzem para o projeto através das definições relativas aos parâmetros estruturais.

De modo resumido, os parâmetros estruturais propostos por Sitter et al. (1997) e retrabalhados por Aulicino (1998) e por Salerno (1999) são:

a) concentração funcional: parâmetro relativo à divisão do trabalho entre as funções do sistema de produção. Diz respeito a como são agrupados ou ligados os subsistemas do sistema de produção em relação ao fluxo de fabricação dos produtos, ou seja, a como se dá a divisão do trabalho ao longo do processo. Duas possibilidades extremas são: atribuição das ordens de produção a todos os subsistemas (como num arranjo funcional de metalúrgicas que trabalham por encomenda fechada, quando a ordem vai para a tornearia, para a seção de fresa, de retífica, para a montagem, etc.), ou atribuição de cada ordem a um subsistema específico, como num arranjo celular, tratando-se no primeiro caso da concentração e no segundo da desconcentração do sistema em fluxos paralelos. A questão central aqui é a paralelização dos fluxos, que aumenta em muito a dirigibilidade do sistema. Vejamos um exemplo: se uma fábrica embala todos os seus produtos numa mesma linha, há muita vulnerabilidade a falhas de equipamento, de operação; o teste de uma nova embalagem ou do envase de um novo produto significa indisponibilizar o equipamento para a produção normal. Já se houvesse duas linhas de capacidade unitária menor, aumentaria a capacidade de fazer frente a eventos, aumentaria a dirigibilidade. No caso dos processos contínuos, onde as unidades de produção são de grande porte, dedicadas, e demandam altos investimentos, a paralelização pode ocorrer, por exemplo, aproveitando uma ampliação da fábrica através da construção de novas unidades (ou plantas). Nesse caso, pode haver a separação de matérias-primas, destinando-as a unidades diferentes, reduzindo as necessidades de ajustes nos processos. Ou a alocação da ordem de produção de determinada especificação de produtos a apenas uma das unidades existentes. Evidentemente, é necessário análise de investimento, pois pode haver ganhos de escala na concentração funcional, mas esses estudos deveriam considerar não a capacidade teórica dos equipamentos mas sim como os equipamentos poderão vir a ser ocupados em função das estratégias da empresa - quanto menos visível for o futuro em termos de produto, configurações de processo, objetivos de produção, etc., mais importante é a paralelização. A definição acerca de concentração e desconcentração é, portanto, decisiva, pois limita a liberdade de definição dos demais parâmetros estruturais.

b) divisão do trabalho entre preparar, apoiar e produzir (diferenciação da execução): refere-se à divisão do trabalho nas funções preparar, apoiar e produzir em subsistemas especializados (ou setores da produção - craqueamento, utilidades, etc.). Por exemplo, como é a divisão de trabalho entre preparação, alimentação e operação de uma parte do processo: essas atividades são atribuídas a uma unidade organizacional só (quando, por exemplo, a operação direta se encarrega de tudo) ou a diversas unidades (quando há um setor que cuida da preparação, outros do apoio e outro ainda da produção direta propriamente dita)? Em um processo contínuo, em uma refinaria de petróleo, há as atividades de preparação - análise do petróleo, decantação, carga, ajuste da unidade de produção e operação propriamente dita. A análise, no caso em estudo, é realizada pelo setor de laboratório, do domínio da engenharia; a preparação e a carga pela gerência de transferência e estocagem; e o ajuste da unidade (de certa forma equivalente ao set up na manufatura), pelo próprio pessoal de operação de processo das unidades, revelando haver divisão de trabalho entre as subfunções de operação e apoio - configura-se uma estrutura organizacional complexa. 
c) divisão do trabalho dentro das subfunções de preparação, apoio e produção (especialização da execução): refere-se ao desmembramento de uma função de execução em subfunções de execução, alocadas em subsistemas separados. Um exemplo de especialização seria quando, ao realizar uma melhoria no sistema de controle operacional de uma das unidades de produção, a equipe de automação da engenharia projeta uma malha de controle, a área especializada de instrumentação da manutenção carrega os parâmetros de controle nos equipamentos digitais de controle, e a equipe de operação da própria unidade testa o sistema. Outro exemplo é quando a área de operação solicita à área de manutenção abrir tampas de equipamentos, fazer instalação temporária de linhas ou instalar instrumentos de medição de temperatura de pressão e vazão para possibilitar-lhe a realização de drenagens e de limpezas de equipamentos, durante a operação das unidades de produção.

d) separação das funções de execução e de controle: locação da execução e seu correspondente controle a subsistemas ou elementos (indivíduos ou máquinas) diferentes. A própria atividade operacional dos processos contínuos é uma atividade de controle, uma vez que os operadores exercem controle sobre os processos de transformação das diversas matérias-primas e produtos intermediários em produtos desejados. Esse controle é exercido tanto sobre as variáreis dos processos (temperaturas, pressões, vazões) quanto sobre as condições de funcionamento dos equipamentos. Entretanto, o controle da produção (PCP), no caso estudado, é exercido pela engenharia de processos, uma vez que o planejamento e controle da produção está intimamente ligado à otimização dos processos, que é uma das atribuições da engenharia.

Com a telemática, engenheiros de processo, especialistas de manutenção e outros podem acompanhar à distância o comportamento das variáveis dos processos de fabricação e dos equipamentos. As informações colhidas nas entrevistas mostram que esses profissionais alertam a Operação e solicitam intervenções operacionais ao constatarem tendências das variáveis monitoradas que podem ocasionar falhas. Por exemplo, o pessoal de manutenção preditiva pode detectar alguma máquina operando fora das faixas de vazão ou pressão consideradas ideais e solicitar ajustes ao pessoal de operação. Nesses casos, pode-se dizer que se trata mais de um compartilhamento do controle, do que uma separação.

e) especialização do controle: alocação do controle de aspectos funcionais a distintos aspectos do sistema, como qualidade, manutenção, logística, pessoal, etc. Um exemplo simples e clássico é atribuir o controle de qualidade a um setor externo à produção direta. Outra situação possível é o estabelecimento de uma divisão de responsabilidades de controle entre as funções manutenção e operação. Na produção por processos contínuos, onde a qualidade dos produtos é medida por ensaios químicos e físicos para determinar as suas propriedades, é comum haver um setor de laboratório especializado na realização desses ensaios - comumente, uma unidade organizacional à parte (controle de qualidade ou assemelhado), ainda que a literatura aponte casos de laboratório e de análises laboratoriais integradas à produção direta (SALERNO, 1999).

f) diferenciação do controle: desmembramento dos domínios de controle em níveis separados: estratégico, estrutural e operacional. Neste parâmetro cabe discutir a formulação e controle de metas. No caso das refinarias de petróleo, a formulação de metas de desempenho relacionadas ao sistema de produção pode depender de simulação dos processos, analisando-se possíveis alternativas para os seus parâmetros, de estudos para atendimento a requisitos de qualidade, ou seja, de propriedades físicas e químicas dos produtos, ou de estudos de capacidade dos equipamentos, dentre outros fatores. Ou seja, a formulação de metas de desempenho demanda conhecimentos e habilidades de domínio dos engenheiros. Essa situação pode fazer com que a formulação e controle dessas metas fiquem a cargo da Engenharia, no nível estrutural, ficando a Operação com o controle operacional. Pode caber aqui também uma divisão do controle segundo uma lógica temporal. Um exemplo foi apresentado por um operador entrevistado, que destacou a capacidade dos engenheiros de anteciparem situações, enquanto os operadores lidam mais com os problemas que se apresentam. Uma hipótese para tanto seria o fato de os engenheiros, em princípio, conhecerem o modelo teórico de equilíbrio do processo, e os operadores não, o que facilitaria a previsão pelos primeiros.

g) divisão das funções de controle: este parâmetro trata da alocação das funções do ciclo de controle, que é composto pela representação (percepção) do estado do processo, julgamento e escolha da ação (SALERNO, 1999). Assim, se o pessoal de laboratório, que analisa as propriedades das matérias-primas e dos produtos, detecta algum valor fora do especificado, cabe a outros setores a identificação das causas e tomada de ações. Ou, se a Operação identifica um problema no processo de produção que não se sente capaz de avaliar, recorre à Engenharia para realizar a avaliação, muitas vezes em conjunto com o pessoal de Operação. Ou ao contrário, quando a Engenharia ou a Manutenção identificam falhas potenciais, indicam à Operação para que se tomem as ações adequadas a evitar essas possíveis falhas. 
O segundo e terceiro parâmetros (respectivamente, concentração funcional e divisão do trabalho entre preparação, apoio e produção) tratam da questão da segmentação, ou seja, das fronteiras de atuação dos grupos nas funções de execução da produção. O princípio aplicável é a internalização aos segmentos das situações de interfaces. Trata-se de reduzir as possibilidades de amplificação das variações nos fluxos dos processos, causadas pelas interfaces entre os diferentes segmentos organizacionais que compõem a estrutura de execução da produção. Objetiva minimizar conflitos e agilizar a detecção e correção de desvios e a atuação relativa a eventos de forma geral. Por exemplo, variações nas características físico-químicas de determinado produto intermediário em um processo contínuo de produção causam variações nas atividades de produção da unidade operacional que recebe e transforma esse produto. As perturbações decorrentes se amplificam se tratadas por segmentos organizacionais diferentes, envolvendo negociações entre pelo menos dois grupos sobre as medidas de contorno e de correção a serem adotadas (SITTER et al., 1997; AULICINO, 1998). Salerno (1999) complementa essa idéia afirmando que a segmentação deve ser pensada para que o ciclo completo de tratamento de um evento - origem/causa, detecção/percepção, análise/diagnóstico e ação/manobra operacional - esteja sobre domínio completo de um único grupo.

Os demais parâmetros definem a estrutura de controle. De modo semelhante ao exposto para a estrutura de execução (operação), sugere-se a aplicação do princípio da unicidade de tempo, local e ação para alocação dos ciclos de controle. Dessa forma, os ciclos de controle devem ser desenhados no sentido bottom-up, alocando a níveis superiores ao indivíduo ou ao grupo de trabalho somente aquilo que eles não puderem controlar (SITTER et al., 1997).

Aulicino (1998) desenvolveu aplicação desses conceitos ao projeto do trabalho em equipes de operadores de refinarias de petróleo. Marx (1997) tratou da autonomia nas equipes de trabalhadores. Salerno (1999) propôs a criação de espaços de comunicação-negociação, fazendo avançar a teoria de projeto organizacional com base, dentre outros, nos conceitos apresentados acima, focando principalmente o que chama de "atuação vertical do operariado" (com relação aos sistemas de apoio e de gestão). Agora, porém, trata-se de discutir os conceitos de projeto organizacional para as situações em que a engenharia participe ativamente do trabalho da operação e da manutenção. Ou seja, a teoria de projeto oferece conceitos e regras para paralelização, segmentação e estruturação dos segmentos organizacionais, inclusive para reduzir as interfaces entre os segmentos, mas é preciso incorporar conceitos e regras para as situações em que ao contrário de dividir o trabalho, ele é realizado de modo integrado por diferentes domínios, tendo em vista as dimensões cognitiva e normativa. Abaixo, são destacados alguns aspectos que devem ser considerados.

No caso das interfaces e relações não rotineiras, como quando da ocorrência de eventos de baixa repetição ou de pouca previsibilidade que exigem a intervenção de mais de uma área, pode-se procurar as formas organizacionais mais adequadas a cada nova situação. Tais formas podem incluir, por exemplo, a formação de grupos de trabalho de geometria variável (SALERNO, 2007), a constituição de estruturas temporárias, a criação de espaços de comunicação e de fóruns decisórios.

Nas interfaces, cabe discutir a alocação de atribuições, expressa nos parâmetros concentração funcional, diferenciação da execução e especialização da execução, pelas opções quanto à paralelização e segmentação. Diferentemente do enfoque voltado à alocação das ordens de produção ou do estabelecimento dos fluxos de fabricação, a questão aqui se volta a como o trabalho é divido ou é integrado nas situações que envolvem mais de um dos domínios.

Um exemplo levantado no caso estudado é o dos fornos, que são equipamentos usuais e importantes nas indústrias de processo contínuo. Na RPBC há um grupo multifuncional composto por técnicos das três áreas, Operação, Manutenção e Engenharia, para verificar as condições dos equipamentos, definir trabalhos de manutenção dos componentes (limpeza periódica, substituição de peças, etc.), definir procedimentos operacionais e apresentar medidas para melhoria de desempenho. Alguns objetivos envolvidos são: eficiência energética, métodos e procedimentos operacionais adequados, custos de operação e de manutenção, segurança e emissões atmosféricas.

Apesar da formação desse grupo de trabalho ser considerada uma boa prática na empresa, um dos entrevistados manifestou que essa forma de trabalho pode ser pouco produtiva, quando o engenheiro ou o especialista da manutenção se concentram em atividades da Operação, muitas vezes em detrimento de outras atividades como o monitoramento da eficiência energética do equipamento, tarefa para a qual o engenheiro deteria os conhecimentos e habilidades necessárias. Nas palavras do entrevistado, às vezes se todos olharem tudo, alguma coisa deixa de ser vista convenientemente.

Uma situação significativa e ilustrativa é a dos sistemas de controle avançado. O projeto organizacional deve prever formas de compartilhar a responsabilidade da operação dos processos de produção entre os engenheiros de automação, que detêm o conhecimento especializado de construção de modelos matemáticos; os operadores, que possuem o saber do funcionamento real dos sistemas operacionais; os instrumentistas e eletricistas, que monitoram o desempenho dos instrumentos e equipamentos 
de controle (DANIELLOU, 1986; KHURANA, 1999; SHOOK, 2006).

A discussão do parâmetro separação das funções de execução e controle remete a questões como o controle da qualidade do próprio trabalho e a possibilidade do trabalhador propor melhorias nas atividades que executa e no seu local de trabalho, já discutidas por diversos autores (FLEURY; VARGAS, 1983; CHERNS, 1979; BIAZZI Jr., 1994; SALERNO, 1999) e uma boa parte dos escritos sobre qualidade total - 5S, CCQ, kaizen, melhoria contínua, etc.

Remete ainda à questão da autonomia dos grupos de trabalho da produção, que pode incluir a autonomia para dividir o trabalho, interromper a produção, definir o ritmo de produção, acionar a manutenção, dentre outras citadas por Marx (1997), que podem ser entendidas como ações de controle dos processos de produção.

Colocada dessa forma, a discussão se restringe ao domínio da operação e, de forma análoga, pode ser feita no âmbito interno da manutenção e da engenharia. Os autores citados, dentre outros, exploraram essas questões dentro de cada domínio (ou função, subsistema funcional). No presente caso, importa verificar o quanto a engenharia, em razão do seu conhecimento técnico, passa a exercer controle sobre o trabalho executado pela operação e pela manutenção, em que níveis esse controle é exercido, como interfere e limita as possibilidades de manobras operacionais, quais os limites de responsabilidade de cada um e como essa atribuição de controle é aceita e entendida por todos os atores (parâmetros estruturais, divisão e especialização do controle).

No projeto organizacional de um sistema complexo como o aqui estudado, deve ser analisado como a Manutenção exerce controle sobre a confiabilidade dos equipamentos, impactada pelas situações operacionais e pelas mudanças nos processos. A experiência da RPBC mostra que a operação tem papel decisivo para a confiabilidade dos equipamentos ao monitorar também os parâmetros que a afetam, como parte da atividade de monitoramento dos processos de fabricação. Está se lidando aqui com o parâmetro diferenciação das funções de controle, envolvendo domínios diferentes.

Na dinâmica dessas fronteiras entre as funções podem surgir problemas: como é aceito e entendido o papel do engenheiro de equipamentos que, ao analisar um problema de confiabilidade de certo sistema ou equipamento, aponta a necessidade de mudanças nos métodos de execução da manutenção? Qual é a responsabilidade e até onde vai a atuação do engenheiro de processo que recomenda mudanças nos parâmetros de controle dos processos, nem sempre bem aceitas pelo pessoal de operação? Pode-se pensar que nesses casos a engenharia "vende" uma idéia, que pode ser aceita ou não. Possíveis consequências vão desde a melhora ampla de diversos indicadores à perda de oportunidade de alcançar bons resultados ou uma série de problemas operacionais decorrentes das mudanças implementadas que são herdados pela operação.

Foi analisado um caso de atuação conjunta das equipes de manutenção mecânica e de engenharia de equipamentos que convenceu a operação a alterar os procedimentos de partida de certas bombas, adequando-os às curvas de desempenho ideais desses equipamentos. Em razão disso, houve redução da taxa de falhas desses equipamentos e aumento de confiabilidade dos sistemas operacionais onde essas bombas estão inseridas.

Outros aspectos ainda podem ser considerados, como a fixação de objetivos e a negociação de metas de produção. Sendo uma característica dos processos contínuos as transformações físicas e químicas, a complexidade, a existência de equipamentos dedicados, o aspecto sistêmico, etc. A proposição e o alcance de metas de produção, tais como atendimento a exigências de qualidade de produto, atingimento de quantidades produzidas de cada fração e índices de redução da emissão de poluentes, podem extrapolar a competência não apenas dos operadores, mas da área de operação. Nesse caso, metas de produção são negociadas com base em estudos e estimativas da área de engenharia, o que pode levar à separação entre a formulação de metas, o seu controle e a execução das atividades de operação e de manutenção do sistema de produção (parâmetro diferenciação do controle), ao mesmo tempo em que reforça a importância da integração nas interfaces existentes.

\section{Mecanismos de coordenação: uma contribuição à teoria de projeto organizacional}

A discussão dos conceitos de projeto organizacional feita acima focou sua aplicação a um caso relevante de processo contínuo, ressaltando a importância do estabelecimento de mecanismos de coordenação para articulação do trabalho nas interfaces entre os domínios. A literatura organizacional trata muito mais da divisão do trabalho do que de sua coordenação. Neste último caso, há abordagens genéricas, como a de Mintzberg (1993), que relaciona categorias de coordenação como definidoras de configurações organizacionais estáveis, e proposições de instrumentos, como elemento de ligação, reuniões, etc.

Podemos identificar instrumentos de coordenação no caso em análise, e discutir sua limitação para nosso tema. Por exemplo, equipes de operadores e supervisores de diferentes especialidades de manutenção que priorizam, planejam, programam e acompanham os trabalhos de manutenção, na RPBC conhecidas como equipes de continuidade operacional, e constituem o fórum de discussão entre os segmentos de operação e de manu- 
tenção acerca do que é prioritário, no curto prazo. Cada supervisor de manutenção traz para a equipe as visões de seu segmento, tanto de gerentes como de executantes, acerca das necessidades mais importantes e urgentes em relação ao funcionamento confiável dos equipamentos e de requisitos de desempenho da manutenção, como aproveitamento da mão-de-obra, custo e disponibilidade dos equipamentos. Os operadores são portadores das necessidades dos segmentos da operação a que pertencem e se constituem no elo com os grupos de operadores que trabalham em turno. Cabe a eles não apenas tratar as solicitações de serviço feitas pelas equipes de turno, como dar retorno a elas e estabelecer um entendimento sobre as prioridades definidas, o planejamento e a programação dos serviços a serem realizados.

Outro mecanismo de coordenação levantado são os grupos multifuncionais para solução de problema, como análise de imprevistos, e para tratamento rotineiro de aspectos do sistema de produção, como o desempenho de fornos. Esses grupos são espaços para reunir conhecimentos e analisar informações de cada domínio ali representado, visando à determinação das causas de problemas, para definição de novos procedimentos de trabalho e para consolidação de planos de ações que envolvem diferentes funções, exercendo um papel de coordenação, mormente em seus registros cognitivo e normativo.

Por fim, as reuniões diárias de produção, constatadas também em outras empresas visitadas pelos pesquisadores. Toda manhã, o coordenador de turno relata a situação das unidades que compõem o sistema de produção, destacando as principais variáveis dos processos, e principais ocorrências acontecidas desde a véspera. Assistem a esse relato gerentes, supervisores, engenheiros, profissionais de segurança industrial e outros. Após tomar conhecimento do relato, os profissionais dos diferentes domínios se reúnem para breve análise dos fatos e para combinarem providências de curto prazo. Por exemplo, para certo segmento da Operação, participam dessa breve reunião; gerente, supervisores, técnicos de operação, engenheiros de processo, membros da equipe de continuidade operacional e, se houver necessidade, técnicos de manutenção e engenheiros da especialidade de equipamentos ligados a algum problema em foco (mecânica, eletricidade, caldeiraria, instrumentação).

Dada a importância dos mecanismos de coordenação essenciais para articular o trabalho dividido em funções, departamentos, seções, postos, etc., que no caso estudado ganha contornos críticos, dados os efeitos de uma descoordenação, será proposto um desdobramento dos conceitos, para projeto organizacional, enunciados por Sitter et al. (1997). O projeto organizacional deve incluir o estabelecimento de mecanismos de coordenação das ações das funções, subsistemas ou domínios organiza- cionais que, sem prejuízo dos enfoques tradicionais da coordenação (divisão do trabalho, sequência, cronologia e monitoramento de ações), possibilitem a integração dos saberes (dimensão cognitiva) e a redefinição conjunta de regras de produção (dimensão normativa). A integração dos saberes e a redefinição de regras de produção são partes fundamentais do trabalho dos domínios organizacionais que atuam diretamente nos sistemas de produção complexos.

A Tabela 1 mostra algumas situações típicas do trabalho em processos contínuos e mecanismos de coordenação, observados nesta pesquisa.

\section{Roteiro para o projeto organizacional integrando operação, manutenção e engenharia em processos contínuos}

Uma vez apresentados e discutidos os conceitos e os parâmetros organizacionais, faz-se necessário tratar os critérios para a elaboração do projeto organizacional do trabalho integrado da operação, manutenção e engenharia.

Partindo do método e do roteiro de projeto elaborados por Sitter et al. (1997) e Salerno (2007, 1999), acrescidos de elementos oriundos das discussões apresentadas neste trabalho, pode ser proposta uma contribuição, visando aperfeiçoar o roteiro para o projeto organizacional, conforme segue:

a) incluir no roteiro para projeto a identificação das atividades ou eventos-tipo, cujo tratamento exige competências que não sejam de domínio dos profissionais da operação, e alocar atividades pertinentes nos domínios da engenharia e da manutenção. A alocação pode significar a simples transferência de atividades entre segmentos ou a criação de atividades conjugadas em domínios diferentes; e

b) contemplar no roteiro de projeto o estabelecimento de mecanismos de coordenação entre operação, engenharia e manutenção que atendam às necessidades do trabalho integrado dos domínios nas dimensões cognitiva e normativa, além das variáveis tradicionais de articulação das ações a serem executadas.

Como foi frisado anteriormente, ocorre antes uma permeabilidade das fronteiras organizacionais, com a Engenharia muitas vezes mesclando-se com a operação (o mesmo ocorrendo com a manutenção), do que uma interface entre duas fronteiras rígidas aptas a mecanismos de coordenação tradicionais (elo de ligação, reuniões, grupos multifuncionais, etc.). Esta é uma caracterização importante, não percebida pelos estudos disponíveis, que só tratam de configurações $a d$ hoc internamente à operação (grupos de geometria variável de SALERNO, 1999, 2007), ou de internalização, num domínio, de atividades 
Tabela 1. Mecanismos de coordenação para a organização do trabalho em processos contínuos. (SALERNO; AULICINO, 2008).

\begin{tabular}{|c|c|c|}
\hline Situações de trabalho & Mecanismos de coordenação & Enfoques cognitivos e normativos \\
\hline $\begin{array}{l}\text { Planejamento, programação e execu- } \\
\text { ção de trabalhos de manutenção. }\end{array}$ & $\begin{array}{l}\text { Equipes constituídas por profissionais dos } \\
\text { domínios participantes. }\end{array}$ & Visão holística das intervenções. \\
\hline \multirow[t]{2}{*}{$\begin{array}{l}\text { Acompanhamento rotineiro dos } \\
\text { processos de produção. }\end{array}$} & Reuniões diárias de produção. & $\begin{array}{l}\text { Avaliação de desvios e tendências dos } \\
\text { parâmetros dos processos integrando diferentes } \\
\text { aspectos e abrangências para orientar ações de } \\
\text { curto prazo. }\end{array}$ \\
\hline & Grupos temáticos. & $\begin{array}{l}\text { Avaliação do desempenho de partes dos } \\
\text { processos e proposição de melhorias. }\end{array}$ \\
\hline Eventos/imprevistos. & Grupos de trabalho de análise e solução. & $\begin{array}{l}\text { Identificação de causas básicas e } \\
\text { estabelecimento de ações. }\end{array}$ \\
\hline Mudanças técnicas nos processos. & $\begin{array}{l}\text { Sistemática de participação de profissionais de } \\
\text { outros domínios nos projetos de engenharia. }\end{array}$ & $\begin{array}{l}\text { Completude dos requisitos e percepções } \\
\text { envolvidos nas mudanças. }\end{array}$ \\
\hline
\end{tabular}

Tabela 2. Contribuições à teoria sociotécnica moderna de projeto organizacional. (SALERNO; AULICINO, 2008).

\begin{tabular}{|c|c|}
\hline $\begin{array}{c}\text { Regras para projeto organizacional do trabalho - } \\
\text { sociotecnologia moderna (SALERNO, 1999) }\end{array}$ & $\begin{array}{c}\text { Contribuições: mudanças propostas } \\
\text { nas regras para projeto organizacional }\end{array}$ \\
\hline Definição dos processos do sistema de produção. & Inalterado. \\
\hline $\begin{array}{l}\text { Paralelização dos Processos: identificação de variabilidades e } \\
\text { criação de fluxos paralelos. }\end{array}$ & Inalterado. \\
\hline $\begin{array}{l}\text { Segmentação dos processos: sentido top-down; internalização de } \\
\text { interfaces. }\end{array}$ & $\begin{array}{l}\text { Acrescentar: identificação de atividades e eventos-tipo que de- } \\
\text { mandem competências de outros domínios; estabelecer atividades } \\
\text { equivalentes em outras funções. }\end{array}$ \\
\hline $\begin{array}{l}\text { Estruturação do trabalho nos segmentos organizacionais: parâme- } \\
\text { tros estruturais de execução. }\end{array}$ & Inalterado. \\
\hline $\begin{array}{l}\text { Estruturação do controle: alocação bottom-up dos ciclos de con- } \\
\text { trole. }\end{array}$ & $\begin{array}{l}\text { Considerar e projetar as situações de compartilhamento do contro- } \\
\text { le com outros domínios. }\end{array}$ \\
\hline Não trata desta etapa. & $\begin{array}{l}\text { Estabelecer mecanismos de coordenação do trabalho integrado dos } \\
\text { domínios organizacionais - dimensões cognitiva e normativa. }\end{array}$ \\
\hline $\begin{array}{l}\text { Projeto do sistema de informações; criação de espaços de comuni- } \\
\text { cação/negociação. }\end{array}$ & Inalterado. \\
\hline
\end{tabular}

antes desempenhadas por outro domínio, para reduzir interfaces (como nas regras de projeto de SITTER et al., 1997, e de SALERNO, 1999). Assim, a Tabela 2 apresenta a comparação entre o roteiro de projeto proposto por Salerno (1999) e o roteiro modificado pelas contribuições acima.

\section{Considerações finais}

Um problema prático - a ação conjunta entre operação, manutenção e engenharia em processos contínuos de alta complexidade - evidenciou uma lacuna conceitual, teórica e metodológica, qual seja, a de projeto organizacional que considere interfaces internas dos sistemas de produção contínuos, contemplando os domínios organizacionais que interagem na sua operação. Esses sistemas, complexos, integrados e automatizados, apresentam necessidade de atuação sistêmica, submetidos a exigências de eficiência operacional, de flexibilidade e ambientais/segurança (prazos, custos, padrões de qualidade/especificações, emissões, prevenção de acidentes, etc.). A pesquisa de campo mostrou que as interfaces são maleáveis, ou seja, as fronteiras se interpenetram: em muitos casos, as funções analisadas atuam conjuntamente para realizar uma atividade de produção, o que não tem sido considerado na literatura.

Seguindo trajetória de estudos organizacionais anteriores sobre sistemas integrados e flexíveis, foi adotada a sociotecnologia (ou sociotécnica) moderna como base para as proposições de um roteiro de projeto organizacional que trate as interfaces abordadas e suas interpenetrações, integradamente. Para abranger essa dimensão de trabalho integrado é necessário que os parâmetros estruturais, as estratégias e o roteiro de projeto organizacional (seqüência de passos) reflitam também a organização das interfaces, estrutural e dinâmica, entre os domínios que atuam diretamente no sistema de produção.

As considerações feitas, evidentemente, estão longe de esgotar o assunto. Rigorosamente, o abrem. Novas pesquisas devem enriquecer as discussões sobre as variações possíveis para os parâmetros estruturais e validar as estratégias e o roteiro de projeto aqui propostos, bem como detalhar o esquema e testá-lo empiricamente. 


\title{
Integrated organizational design for operations, engineering and maintenance in continuous process production: a pratical issue and a conceptual gap
}

\begin{abstract}
Engineering and Maintenance participate strongly in continuous process operations. They determine process control parameters; act decisively in production events; solve complex problems; and design modifications in production processes and hardware aimed at achieving productive, economic and environmental goals. On the other hand, Operations teams possess pragmatic knowledge of operational procedures, of hardware responses to process control commands, and of changes in production processes such as equipment failures or new production parameters. Their knowledge must therefore influence Engineering and Maintenance teams. However, there is no theoretical framework to support organizational design that brings together the three functions through interfaces. This paper therefore aims to fill that gap.
\end{abstract}

Keywords: Organizational design. Job organization. Continuous process production. Engineering. Production and maintenance integration. Sociotechnical systems.

\section{Referências bibliográficas}

AULICINO, M. C. Elementos para Projeto de Organização do Trabalho na Operação de Processos Contínuos: Considerações a Partir de um Estudo de Caso. São Paulo, 1998. 199 p. Dissertação - (Mestrado em Engenharia de Produção), Departamento de Engenharia de Produção, Escola Politécnica, Universidade de São Paulo - USP.

BIAZZI Jr., F. O trabalho e as organizações na perspectiva sóciotécnica. Revista de Administração de Empresas, São Paulo, v. 34, n. 1, p. 30-37, jan./fev. 1994.

BOUYER, G. C.; SZNELWAR, L. I. Análise Cognitiva do Processo de Trabalho em Sistemas Complexos de Operações. Ciências \& Cognição (UFRJ), Rio de Janeiro, v. 4, n.2, p. 2-24, 2005.

CHERNS, A. The principles of sociotechnical design. In: Using the social sciences. London: Routledge \& Kegan Paul, 1979. Cap.16, p.30-40.

DANIELLOU, F. L'operateur, la vanne, l'ecran. l'ergonomie des salles de contrôle. Paris : Laboratoire d'Ergonomie, Conservatoire National des Arts e Metiers, 1986.

EISENHARDT, K. M. Building theories from case study research. The Academy of Management Review, Cambridge (MA), v. 14, n. 4 , p. $532-550$, Oct. 1989.

FERREIRA, L. L.; IGUTI, A. M. O trabalho dos petroleiros: perigoso, complexo, contínuo e coletivo. São Paulo: Scritta, 1996. $152 \mathrm{p}$.

FLEURY, A. C. C.; VARGAS, N. Organização do trabalho: uma abordagem interdisciplinar. São Paulo: Atlas, 1983. 232 p.

GRATTON, L.; VOIGT, A.; ERICKSON, T. J. Bridging fault lines in diverse teams. Sloan Management Review, Cambridge (MA), v. 48, n. 4, p. 22-29, summer 2007.

KHURANA, A. Managing complex production processes. Sloan Management Review, Cambridge (MA), v.40, n.2, p.85-97, Winter 1999.

MINTZBERG, H. Strutcture in fives: designing effective organizations. Englewood Cliffs: Prentice Hall, 1993. 312 p.

MARX, R. Trabalho em grupos e autonomia como instrumentos da competição. São Paulo: Atlas, 1997. 165 p.
RAMOS FILHO, A. C. A evolução tecnológica e a gestão do trabalho na indústria de processo: o caso da Petrobrás. Rio de Janeiro, 1997. Dissertação - (Mestrado em Administração de Empresas), Pontifícia Universidade Católica do Rio de Janeiro. (sem paginação definida)

SALERNO, M. S. Reconfigurable organization to cope with unpredictable goals. In: INTERNATIONAL CONFERENCE OF PRODUCTION RESEARCH - ICPR, 19, 2007, Santiago. Proceedings... Santiago, 2007. (CD-ROM).

Projeto de organizações integradas e flexíveis: processos, grupos e gestão democrática via espaços de comunicação negociação. São Paulo: Atlas, 1999. 215 p.

SHOOK, D. Best practices improve control system performance. Oil \& Gas Journal, Tulsa (Oklahoma), v.104, n.38, p. 52-59, Oct. 2006.

SITTER, U. L.; HERTOG, J. F.; DANKBAAR, B. From complex organizations with simple jobs to simple organizations with complex jobs. Human Relations, Londres, v. 50, n. 5, p.497-534, 1997.

THIOLLENT, M. Pesquisa-ação nas organizações. São Paulo: Atlas, 1997, $164 \mathrm{p}$.

VELTZ, P. Le nouveau monde industriel. Paris: Gallimard, 2000. $230 \mathrm{p}$.

VOSS, C.; TSIKRIKTSIS, N.; FROHLICH, M. Case research in operations management. International Journal of Operations \& Production Management, Bingley (UK), v. 22, n. 2, p. 195-219, 2005.

WORLEY, C.G.; LAWLER III, E.E. Designing organizations that are built to change. Sloan Management Review, Cambridge (MA), v. 48, n. 1, p. 19-23, Fall 2006.

ZARIFIAN, P. Travail et communication: essai sociologique sur le travail dans la grande entreprise industrielle. Paris: PUF, 1996. 213 p. 
Sobre os autores

\section{Mario Sergio Salerno}

Departamento de Engenharia de Produção da Escola Politécnica da USP,

Av. Prof. Almeida Prado, Trav. 2, n 128 , CEP 05508-900, São Paulo, SP, Brasil,

e-mail: msalerno@usp.br

\section{Marcelo Crescenti Aulicino}

Departamento de Engenharia de Produção da Escola Politécnica da USP,

Petrobras S.A., Refinaria Presidente Bernardes, Cubatão,

Praça Mal. Stenio Caio de Albuquerque Lima, 1, CEP 11555-900, Cubatão, SP, Brasil,

e-mail: m.aulicino@ petrobras.com.br 